\title{
Influence of oral magnesium supplementation on cardiac events among survivors of an acute myocardial infarction
}

\author{
Anders M Galløe, Henrik S Rasmussen, Lars N Jørgensen, Peter Aurup, Sten Balsløv, \\ Cristina Cintin, Niels Graudal, Peter McNair
}

\section{Abstract}

Objective-To investigate the effect of long term oral magnesium treatment on incidence of cardiac events among survivors of an acute myocardial infarction.

Design-Double blind, placebo controlled parallel study in which patients were randomised to treatment or placebo.

Setting-Two coronary care units and corresponding outpatient clinics.

Subjects-468 survivors of an acute myocardial infarction (289 men and 178 women) aged 31-92.

Interventions-One tablet of $15 \mathrm{mmol}$ magnesium hydroxide or placebo daily for one year.

Main outcome measures-Incidences of reinfarction, sudden death, and coronary artery bypass grafting in one year.

Results-There was no significant difference between treatment and placebo groups in the incidence of each of the three cardiac events, but when the events were combined and drop outs were excluded from calculations there was a significantly higher incidence of events in the treatment group (56/167 $v$ 33/153; relative risk 1.55 (95\% confidence interval 1.07 to $2 \cdot 25) ; p=0.02$ ). When the timing of events was incorporated by means of a KaplanMeier plot the treatment group showed a significantly higher incidence of events whether drop outs were included or excluded $(p<0.025)$.

Conclusion-Long term oral treatment with 15 mmol magnesium daily does not reduce the incidence of cardiac events in survivors of an acute myocardial infarction and, indeed, seems to increase the risk of developing a cardiac event. Consequently, this treatment cannot be recommended as secondary prophylaxis for such patients.

ebjerg Hospital, 2400 Copenhagen, Denmark Anders M Galløe, registrar Lars N Jørgensen, registrar Sten Balsløv, registrar

Niels Graudal, registrar

Department of Medicine A, Hvidovre Hospital, 2650 Hvidovre, Denmark

Henrik S Rasmussen, registrar

Peter Aurup, registrar

Cristina Cintin, registrar

Department of Clinical Chemistry, Hvidovre Hospital

Peter McNair, consultant

Correspondence to:

Dr A M Galløe, Viggo

Rothesvejl, 2920

Charlottenlund,

DK-Denmark.

$B M \Im$ 1993;307:585-7 with chronic ischaemic heart disease, particularly those treated with diuretics or digoxin, become deficient in magnesium. ${ }^{6-9}$ It has been suggested that this magnesium deficiency predisposes patients to sudden cardiac death, ${ }^{10}$ reinfarction, and other serious cardiac events. ${ }^{11}$

In view of the short term effects of intravenous magnesium on patients with acute myocardial infarction, it is logical to investigate whether long term treatment with magnesium may extend these benefits into the period after the acute phase of a myocardial infarction, especially if magnesium deficiency is a predisposing factor. The present study was designed to evaluate whether such long term treatment with oral magnesium was capable of reducing the incidence of serious cardiac events.

\section{Patients and methods}

During 18 months patients admitted to the coronary care units of two university hospitals in Copenhagen were included in the study if they had survived an acute myocardial infarction, gave informed consent, and escaped the exclusion criteria of second or third degree atrioventricular or sinoatrial blockade or a serum creatinine concentration above $0.200 \mathrm{mmol} / \mathrm{l}$. Before being discharged these patients were randomly assigned to one of two study groups (magnesium treatment or placebo) by means of a single sequence of computer generated random numbers. The tablets used in the study (prepared by Gunnar Kjems Chemistry, Copenhagen) were all similar in appearance and taste and either contained $15 \mathrm{mmol}$ magnesium hydroxide (MABLET) each, equal to the recommended daily dietary allowance of magnesium, ${ }^{12}$ or were composed of starch (placebo). By giving a dose of magnesium equal to the recommended daily dietary allowance in addition to the usual diet we hoped that any magnesium deficiency would be corrected and prevented. The bioavailability of the magnesium hydroxide had been evaluated in another study: urinary excretion of magnesium had been almost doubled compared with placebo. ${ }^{13}$

The patients were asked to start treatment, one tablet a day, on their first day at home and to come to the outpatient clinic for examination at 13,26, and 52 weeks after randomisation. Patients who did not attend were recalled, and only those who ignored this recall or who asked to withdraw from the study were classed as drop outs. On each visit to the clinic the patients were given a new bottle of tablets, and their old bottles were collected.

In Denmark the two principal diagnoses responsible for a patient's admission to hospital are reported to a central register of health. Sudden deaths occurring outside hospital are recorded in the same register. We searched this register for details of hospital admissions and sudden deaths among the participating patients. When necessary, we obtained case records from other hospitals and death certificates from the national board of health. Only cases of sudden death, verified diagnoses of reinfarction, or coronary artery bypass opera- 
tions were accepted as cardiac events. Death in hospital due to reinfarction was classified as reinfarction. If a patient had more than one cardiac event only the first event was included in the statistical analysis. Thus the three end point measurements were fully independent. These events were classified before the patients' treatments were revealed. Serum concentrations of sodium, potassium, calcium, creatinine, albumin, magnesium, and phosphate were measured in patients' blood samples taken before randomisation to the study and 13, 26, and 52 weeks after randomisation. The study was approved by the regional ethics committee and by the Danish National Board of Health.

Calculations of sample sizes had indicated that 600 patients would be sufficient to detect a decrease in the incidence of cardiac events from $16 \%$ to $8 \%$ with a level of significance at 0.05 and a power of 0.80 . The trial was given 18 months to accomplish this. Eventually, only 502 patients were recruited, but the period of recruitment could not be extended because the participating departments had agreed to join an international multicentre study including the same category of patients. Consequently the power of the study was reduced to $0 \cdot 75$. The results were analysed both on an

TABLE I-Baseline characteristics of 468 survivors of an acute myocardial infarction who were randomised to oral magnesium treatment or placebo. Values are means (standard deviations) unless stated otherwise

\begin{tabular}{lcc}
\hline & Treatment group & Placebo group \\
\hline Age (years) & $67 \cdot 3(10 \cdot 5)$ & $67 \cdot 8(11 \cdot 1)$ \\
Age range (years) & $32 \cdot 2-87 \cdot 9$ & $31 \cdot 2-92 \cdot 2$ \\
No of men:women & $146: 88$ & $143: 90$ \\
Blood pressure (mm Hg): & & \\
Systolic & $124(21)$ & $124(22)$ \\
Diastolic & $71(13)$ & $72(12)$ \\
Heat rate (beats/min) & $81(17)$ & $86(14)$ \\
Weight (kg) & $74(15)$ & $72(15)$ \\
Serum concentrations (mmol/l): & $0 \cdot 85(0 \cdot 10)$ & $0 \cdot 84(0 \cdot 11)$ \\
Magnesium & $2 \cdot 38(0 \cdot 16)$ & $2 \cdot 38(0 \cdot 15)$ \\
Calcium & $3.95(0.43)$ & $3.96(0.49)$ \\
Potassium & $140(4)$ & $140(4)$ \\
Sodium & $0 \cdot 112(0.027)$ & $0 \cdot 121(0.029)$ \\
Creatinine & $529(54)$ & $519(61)$ \\
Albumin & $1.14(0 \cdot 17)$ & $1 \cdot 12(0 \cdot 15)$ \\
Phosphate & & \\
\hline
\end{tabular}

TABLE II-Numbers of cardiac events and drop outs among survivors of an acute myocardial infarction who were randomised to oral magnesium treatment or placebo

\begin{tabular}{|c|c|c|}
\hline & $\begin{array}{l}\text { Treatment group } \\
(\mathrm{n}=251)\end{array}$ & $\begin{array}{c}\text { Placebo group } \\
(\mathrm{n}=251)\end{array}$ \\
\hline \multicolumn{3}{|c|}{ Before discharge from hospital } \\
\hline Died & 9 & 8 \\
\hline Withdrew from study & 3 & 7 \\
\hline Lost to follow up & 4 & 3 \\
\hline Remainder & 235 & 233 \\
\hline \multicolumn{3}{|c|}{ By 13 weeks after randomisation } \\
\hline \multicolumn{3}{|l|}{ Cardiac events: } \\
\hline Reinfarction & 19 & 15 \\
\hline Coronary artery bypass & 1 & 1 \\
\hline Sudden death & 11 & 7 \\
\hline \multicolumn{3}{|l|}{ Drop outs: } \\
\hline Death not due to cardiac event & 3 & 3 \\
\hline Non-attendance & 40 & 58 \\
\hline Remainder & 161 & 149 \\
\hline \multicolumn{3}{|c|}{ By 26 weeks after randomisation } \\
\hline \multicolumn{3}{|l|}{ Cardiac events: } \\
\hline Reinfarction & 7 & 1 \\
\hline Coronary artery bypass & 0 & 0 \\
\hline Sudden death & 2 & 2 \\
\hline \multicolumn{3}{|l|}{ Drop outs: } \\
\hline Death not due to cardiac event & 2 & 1 \\
\hline Non-attendance & 12 & 9 \\
\hline Remainder & 138 & 136 \\
\hline \multicolumn{3}{|c|}{ By 52 weeks after randomisation } \\
\hline \multicolumn{3}{|l|}{ Cardiac events: } \\
\hline Reinfarction & 10 & 7 \\
\hline Coronary artery bypass & 3 & 0 \\
\hline Sudden death & 3 & 0 \\
\hline \multicolumn{3}{|l|}{ Drop outs: } \\
\hline Death not due to cardiac event & 3 & 0 \\
\hline Non-attendance & 8 & 9 \\
\hline Remainder & 111 & 120 \\
\hline
\end{tabular}

TABLE III-Incidence of cardiac events among survivors of an acute myocardial infarction who were randomised to oral magnesium treatment or placebo

\begin{tabular}{|c|c|c|c|c|}
\hline & \multicolumn{2}{|c|}{ No (\%) of cardiac events } & \multirow[b]{2}{*}{$\begin{array}{c}\text { Relative risk } \\
\text { (95\% confidence } \\
\text { interval) }\end{array}$} & \multirow[b]{2}{*}{$\begin{array}{l}\text { p Value } \\
\text { (Fisher's } \\
\text { exact test }\end{array}$} \\
\hline & $\begin{array}{l}\text { Treatment } \\
\text { group }\end{array}$ & $\begin{array}{l}\text { Placebo } \\
\text { group }\end{array}$ & & \\
\hline \multicolumn{5}{|c|}{ Including drop outs } \\
\hline $\begin{array}{l}\text { No of subjects } \\
\text { Cardiac events }{ }^{\star} \text { : } \\
\text { Reinfarction } \\
\text { Coronary }\end{array}$ & $\begin{array}{c}235 \\
58(24 \cdot 7) \\
37(15 \cdot 7)\end{array}$ & $\begin{array}{c}233 \\
41(17 \cdot 6) \\
27(11 \cdot 6)\end{array}$ & $\begin{array}{l}1.40(0.98 \text { to } 2.00) \\
1.36(0.86 \text { to } 2.16)\end{array}$ & $\begin{array}{l}0.08 \\
0.23\end{array}$ \\
\hline $\begin{array}{l}\text { bypass } \\
\text { Sudden death }\end{array}$ & $\begin{array}{r}5(2 \cdot 1) \\
16(6 \cdot 8)\end{array}$ & $\begin{array}{r}1(0 \cdot 4) \\
13(5 \cdot 6)\end{array}$ & $\begin{array}{l}4.79(0.60 \text { to } 38.30) \\
1.22(0.60 \text { to } 2.47)\end{array}$ & $\begin{array}{l}0.22 \\
0.70\end{array}$ \\
\hline \multicolumn{5}{|c|}{ Excluding drop outs } \\
\hline $\begin{array}{l}\text { No of subjects } \\
\text { Cardiac events: } \\
\text { Reinfarction } \\
\text { Coronary }\end{array}$ & $\begin{array}{c}167 \\
56(33 \cdot 5) \\
36(21 \cdot 6)\end{array}$ & $\begin{array}{c}153 \\
33(21 \cdot 6) \\
23(15 \cdot 0)\end{array}$ & $\begin{array}{l}1.55(1.07 \text { to } 2.25) \\
1.43(0.89 \text { to } 2.31)\end{array}$ & $\begin{array}{l}0.02 \\
0.15\end{array}$ \\
\hline $\begin{array}{l}\text { bypass } \\
\text { Sudden death }\end{array}$ & $\begin{array}{r}4(2 \cdot 4) \\
16(9 \cdot 6)\end{array}$ & $\begin{array}{l}1(0 \cdot 4) \\
9(5 \cdot 9)\end{array}$ & $\begin{array}{l}3.54(0.42 \text { to } 29.55) \\
1.63(0.74 \text { to } 2.25)\end{array}$ & $\begin{array}{l}0.37 \\
0.30\end{array}$ \\
\hline
\end{tabular}

*Including 10 drop outs whose outcomes were traced in central register of health.

intention to treat basis-including events for drop outs-and after exclusion of events for drop outs as censored observations. The results were compared by means of a Kaplan-Meier plot and a log rank test. ${ }^{14}$ The relative risks of each of the three cardiac events and of any event were calculated and were compared by means of $95 \%$ confidence intervals and Fisher's test of exact probability.

\section{Results}

Table I shows the patients' baseline characteristics. There were no significant changes in the results of any of the blood tests measured at 13,26, and 52 weeks after randomisation. The mean (SD) serum magnesium concentrations of the treatment group and placebo group were not significantly different at baseline $(0.85$ $(0.10) v 0.84(0.11) \mathrm{mmol} / \mathrm{l})$ or at 13,26 , or 52 weeks after randomisation $(0.86(0.11) v 0.82(0.10), 0.86$ $(0.09) v 0.84(0.09)$, and $0.85(0.10) v 0.86(0.09)$ $\mathrm{mmol} / \mathrm{l})$ although the difference at 13 weeks was borderline significant $(p=0.08)$. Six patients in the placebo group and five patients in the treatment group had serum magnesium concentrations below the normal range limit of $0.70 \mathrm{mmol} / \mathrm{l}$.

Table II shows the occurrence of cardiac events and of patients dropping out during the study. Eight patients in the treatment group and four in the placebo group dropped out because of deaths not due to myocardial infarction. The remaining drop outs failed to appear in the outpatient clinic and either ignored their recall or informed us that they wished to withdraw. The fate of all drop outs, however, was ascertained from the central register of health described above.

Table III shows the incidence of cardiac events in the two groups, both including and excluding drop outs. There was no significant difference between the groups in the incidence of each of the three cardiac events, but when the events were assessed together and drop outs were excluded there was a significantly higher incidence of events in the treatment group (relative risk 1.55 ( $95 \%$ confidence interval 1.07 to $2 \cdot 25)$ ). As well as analysing the total number of events in one year, we included the timing of the events by means of a Kaplan-Meier plot and evaluated the significance level by a logrank test. ${ }^{14}$ There was no significant difference in the incidence of reinfarction whether on an intention to treat basis $(p>0.05)$ or after excluding drop outs $(p>0 \cdot 1)$. When sudden deaths and reinfarctions were pooled, however, the treatment group showed a significantly higher incidence than the placebo group on an intention to treat basis $(p<0.05)$ and after excluding drop outs $(p<0 \cdot 05)$. When all three cardiac 


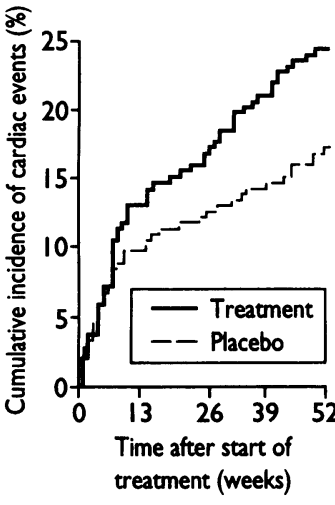

Cumulative incidence of cardiac events over time among survivors of an acute myocardial infarction who were randomised to oral magnesium treatmentorplacebo.

Incidence calculated on an intention to treat basis) events were pooled the significance was increased with both inclusion and exclusion of drop outs $(p<0.025)$. The figure shows the relation between the duration of treatment and the accumulating number of cardiac events in the two groups on an intention to treat basis.

\section{Discussion}

Patients with acute myocardial infarction often have magnesium deficiency ${ }^{6-915}$ and develop an additional hypomagnesaemia during the acute phase of the infarct. ${ }^{15-19}$ Acute treatment with intravenous magnesium not only prevents the transient hypomagnesaemia but induces a hypermagnesaemia, increasing the serum magnesium concentration by 30 $100 \% .^{1920}$ Hence, the beneficial effect of intravenous magnesium treatment may be ascribed to hypermagnesiaemia rather than the correction of hypomagnesaemia. Our protocol of treatment with oral magnesium supplements was not expected to induce significant changes in serum magnesium concentrations: the treatment had previously been shown to nearly double the urinary excretion of magnesium but did not induce changes in serum magnesium concentration. ${ }^{13}$ In accordance with this we could not detect a significant increase in serum magnesium.

We found no beneficial effect of magnesium supplementation as compared with placebo, and, surprisingly, placebo seemed superior to magnesium: when evaluated on an intention to treat basis the treatment group had $37 \%$ more cardiac events than the placebo group, and when drop outs were excluded the treatment group had $55 \%$ more events. When the timing of the events was included the significance level increased. The magnesium treatment's lack of a beneficial effect could be ascribed to an insufficient dosage or insufficient bioavailability. If so, the increased incidence of events in the treatment group could be an

\begin{tabular}{|l|}
\hline Clinical implications \\
\hline Many patients with chronic ischaemic heart \\
disease become deficient in magnesium, and this \\
is thought to predispose them to serious cardiac \\
events \\
- Intravenous infusion of magnesium in the \\
acute phase of a myocardial infarction signifi- \\
cantly reduces mortality \\
- We studied the effects of long term peroral \\
treatment with magnesium on patients who had \\
survived an acute myocardial infarction \\
- After one year the incidence of cardiac events \\
was 55\% higher in the group treated with \\
magnesium compared with controls \\
- Peroral treatment with magnesium cannot be \\
recommended for patients who have survived an \\
acute myocardial infarction
\end{tabular}

example of the type I statistical error. Since magnesium treatment was significantly more harmful than placebo, however, the risk of a type I error is less than 0.05 , and there is no risk of a type II error. This means there is also a very low risk $(<0.0001)$ of committing a type III error-of not detecting that magnesium supplementation should significantly reduce the incidence of cardiac events compared with placebo.

If the difference in the incidence of events between the two groups was caused by the treatment then a sufficient amount of magnesium must have been absorbed to produce that effect. Consequently, it is hard to believe that a larger dose of magnesium could have produced an effect in the opposite direction. It will be interesting to learn from future studies whether the present study is the first to detect potential harm from oral magnesium treatment or whether it is an example of a type I error.

1 Teo KK, Yusuf S, Collins R, Held PH, Peto R. Effects of intravenous magnesium in suspected myocardial infarction: overview of randomised trials. $B M$ f 1991;303:1499-503.

2 Rasmussen HS, McNair P, Backer V, Nørregård P, Lindeneg O, Balsløv S Intravenous magnesium in acute myocardial infarction. Lancet 1986; 234-6.

3 Rasmussen HS, McNair P. Magnesium infusion in acute myocardial infarction. Lancet 1986;:551-2.

4 Rasmussen HS, Grønbæk M, Balsløv S, Cintin C, Nerregård P, McNair P. One year death rate in 270 patients with suspected acute myocardial infarction initially treated with intravenous magnesium or placebo. Clin Cardiol 1988;11:377-81.

5 Morton BC, Nair RC, Smith FM, McKibbon TG, Poznanski WJ. Magnesium therapy in acute myocardial infarction: a double-blind study. Magnesium 1984;3:346-52.

$6 \mathrm{Lim} \mathrm{P}$, Jacob E. Magnesium deficiency in patients on long term diuretic treatment for heart failure. $B M \mathcal{F} 1972 ;$ iii: 620-2.

7 Dyckner T, Webster PO. Intracellular magnesium loss after diuretic administration. Drugs 1984;28(suppl 1):161-6.

8 Ryzen E, Elkayam U, Rude RK. Low blood mononuclear cell magnesium in intensive care unit patients. Am Hear f 1986;111:475-80.

9 Rasmussen HS, McNair P, Geranson L, Balsløv S, Larsen OG, Aurup P. Magnesium deficiency in patients with ischemic heart disease, with an without acure myocardial infarction, uncovered by intravenous loading test. Arch Intern Med 1988;148:329-32.

10 Altura BM, Altura BT. Magnesium ions and contraction of vascular smooth muscles: relationship to some vascular diseases. Fed Proc 1981;40:2672-9.

11 Altura BM, Altura BT, Carella A, Turlapaty PD. Hypomagnesemia and vascoconstriction: possible relationship to etiology of sudden death, ischaemic heart disease and hypertensive vascular disease. Arery 1981;9: 212-31.

12 Ganong WF. Review of medical physiology. 8th ed. Los Alto, California: Lange Medical Publications, 1977: 232

13 Rudnicki M, Frelich A, Fisher-Rasmussen W. Magnesium supplements in pregnancy-induced hypertension: effects of maternal and neonata magnesium and calcium homeostasis. Miner Electrolyte Metab 1991;17:399403.

14 Matthews DE, Farewell VT. Using and understanding medical statistics. 2nd rev ed. London: Karger, 1988:79,178.

15 Abraham AS, Eylath U, Weinstein M, Czaczkes E. Serum magnesium levels in patients with acute myocardial infarction. N Engl f Med 1977;296:862-3.

16 Petersen B, Christiansen C, Transbel I. Blood minerals in cardiac emergencies. Dan Med Bull 1978;25:116-8.

17 Flink EB, Brick JE, Shane SR. Alterations of long chain free fatty acids and magnesium concentrations in acute myocardial infarctions. Arch Intern Med 1981;141:441-3.

18 Rector WG, DeWood MA, Williams RV, Sullivan JF. Serum magnesium and copper levels in acute myocardial infarction. Am $\mathcal{F}$ Med Sci 1981;281:25-9.

19 Rasmussen HS, Aurup P, Højbjerg S, Jensen EK, McNair P. Transien hypomagnesemia not induced by renal magnesium loss in patients with acute myocardial infarction. Arch Intern Med 1986;146:872-4.

20 Woods KI, Fletcher S, Roffe C, Haider Y. Intravenous magnesium sulphate in suspected acute myocardial infarction: results of the second Leicester intravenous magnesium intervention trial (LIMIT-2). Lancet 1992;339. $1553-8$

(Accepted 15 fune 1993) 